\title{
Crescimento inicial de cultivares de algodoeiro submetido ao estresse salino
}

\author{
Álvaro Alberto Pedro ${ }^{1}$, Fábio Steiner ${ }^{1}$, Alan Mario Zuffo ${ }^{1}$, Gabriel Zanuto Douradinho, \\ Camilla Paulino de Oliveira ${ }^{1}$ \\ ${ }^{1}$ Universidade Estadual de Mato Grosso do Sul, Unidade Universitária de Cassilândia, Cassilândia, Mato Grosso do Sul, Brasil. \\ E-mail: steiner@uems.br, alan_zuffo@hotmail.com, gabriel.douradinho@gmail.com
}

Recebido: 14/07/2016; Aceito: 23/09/2016

\section{RESUMO}

A seleção de cultivares de algodoeiro com maior tolerância ao estresse salino pode melhorar a emergência das plantas e garantir a adequada uniformidade de estande. Este estudo teve como objetivo comparar a tolerância à salinidade de cultivares de algodoeiro (Gossypium hirsutum L.) durante a fase inicial de crescimento das plântulas. Os tratamentos foram constituídos por seis cultivares de algodão (FM 910, FM 980 GLT, TMG 42 WS, TMG 82 WS, DP 1240 B2RR e DP 1228 B2R) e por cinco níveis de condutividade elétrica da água de irrigação $\left[0,0 ; 2,5 ; 5,0,10,0\right.$ e 20,0 dS m$\left.~^{-1}\right]$. Os cultivares de algodão DP 1228 B2RF e DP 1240 B2RR apresentaram os melhores índices de emergência das plântulas até o nível de salinidade de $10,0 \mathrm{dS} \mathrm{m}^{-1}$, sugerindo que estes cultivares são moderadamente tolerantes ao estresse salino durante a fase de germinação das sementes; todavia, $o$ crescimento inicial desses cultivares foram afetados negativamente a partir da condutividade elétrica de 2,5 e 5,0 dS $\mathrm{m}^{-1}$, respectivamente. Os cultivares de algodão FM 910, FM 980 GLT e TMG 42 WS são mais susceptíveis aos efeitos negativos do estresse salino por apresentarem os menores índices de emergência e menor taxa de crescimento das plântulas. Altas concentrações de salinidade $\left(20,0 \mathrm{dS} \mathrm{m}^{-1}\right)$ inibem completamente o processo de germinação de todos os cultivares estudados.

Palavras-chave: Gossypium hirsutum L., salinidade, tolerância, emergência, taxa de crescimento.

\section{Initial growth of cotton cultivars under saline stress}

\begin{abstract}
The selection of cotton cultivars with greater tolerance to salt stress can improve plant emergency and ensure adequate uniformity stand. This study aimed to compare the salinity tolerance of cotton cultivars (Gossypium hirsutum L.) during the early stage of seedling growth. The treatments consisted of six cotton cultivars (FM 910, FM 980 GLT, TMG $42 \mathrm{WS}$, TMG $82 \mathrm{WS}$, DP 1240 B2RR and DP 1228 B2R) and five levels of electrical conductivity of irrigation water $\left(0.0 ; 2.5 ; 5.0,10.0\right.$ and $\left.20.0 \mathrm{dS} \mathrm{m}^{-1}\right)$. The cotton cultivars DP $1228 \mathrm{~B} 2 \mathrm{RF}$ and DP $1240 \mathrm{~B} 2 \mathrm{RR}$ showed better emergence rate index of seedlings to the salinity level of $10.0 \mathrm{dS} \mathrm{m}^{-1}$, suggesting that these cultivars are moderately tolerant to salt stress during the phase of seed germination; however, the initial growth of these cultivars were adversely affected from the electric conductivity of 2.5 and $5.0 \mathrm{dS} \mathrm{m}^{-1}$, respectively. Cotton cultivars FM 910, FM 980 GLT and TMG 42 WS are more susceptible to the negative effects of salt stress by having the lower emergence rates and early growth rate of seedlings. High salinity concentrations $\left(20.0 \mathrm{dS} \mathrm{m}^{-1}\right)$ completely inhibited the process of emergence of all studied cultivars.
\end{abstract}

Key words: Gossypium hirsutum L., salinity, tolerance, emergence, plant growth rate. 


\section{Introdução}

A salinidade provocada pelo excesso de sais dissolvidos na solução do solo, ou mesmo na água de irrigação, é um dos estresses abióticos que mais limita o crescimento das plantas e a produtividade agrícola (ZHU, 2001). Este fato é mais expressivo nas regiões áridas e semiáridas as quais apresentam grandes contrastes ambientais (PARIDA; DAS, 2004). Atualmente, estima-se que cerca de $20 \%$ das terras cultivadas e, aproximadamente, metade das áreas irrigadas no mundo apresentam limitações impostas pela salinidade. Estas áreas estão distribuídas, principalmente, na Austrália, Ásia, América do Sul e África.

No Brasil, existem cerca de 16 milhões de hectares de solos salinos e sódicos ( $2 \%$ do território nacional), localizados no Rio Grande do Sul, no Pantanal matogrossense e, principalmente, na região semiárida do Nordeste (RIBEIRO et al., 2003). Em geral, os solos que apresentam valores de condutividade elétrica maior que $4 \mathrm{dS} \mathrm{m}{ }^{-1}$ ou potencial osmótico menor que $-0,117$ MPa são definidos como solos salinos (BRUNES et al., 2013).

A redução do crescimento vegetal causada pela salinidade é decorrente de seus efeitos osmóticos, fitotóxicos e nutricionais (MUNNS, 2002), causando distúrbios funcionais e injúrias no metabolismo das plantas (DEBOUBA et al., 2006; MUNNS; TESTER, 2008). O excesso de sais na solução do solo altera a capacidade das plantas de absorver, transportar e utilizar os íons necessários para o seu crescimento e desenvolvimento (PARIDA; DAS, 2005; FEIJÃO et al., 2011). O desequilíbrio nutricional causado pela salinidade ocorre devido à competição na absorção e transporte dos nutrientes essenciais, às alterações estruturais na membrana e à inibição da atividade de várias enzimas-chave do metabolismo (ZHU, 2001; PARIDA; DAS, 2005; ARAGÃO et al., 2010.

Cramer et al. (1994) afirmam que o grau com que cada um dos componentes do estresse salino influencia a nutrição mineral das plantas é dependente de muitos fatores, dentre eles o cultivar, a intensidade e duração do estresse salino, o teor de água no solo e o estádio de desenvolvimento da planta.

Pesquisas realizadas permitem observar que a salinização induzida com excesso de fertilizantes aplicados no solo é menos incisiva na redução da produtividade que a salinização ocasionada pelo acúmulo de sais provindos de água de irrigação de qualidade marginal (SILVA et al., 2005; DIAS et al., 2005; MEDEIROS et al., 2009). Resultados como os apresentados por Maas e Hoffman (1977) reportaram a salinidade limiar sempre associada à salinidade ocasionada pelo acúmulo de sais não nutrientes. Entretanto, caso o aumento da salinidade seja consequência do acúmulo de fertilizantes no solo, há possibilidade de um aumento de produtividade compensando o efeito negativo da diminuição do potencial osmótico da solução.

A salinidade do solo reduz a disponibilidade da água na solução no solo, todavia, cada espécie vegetal possui um limite de tolerância, denominado 'salinidade limiar' (SL), acima do qual o seu rendimento é reduzido com o incremento da salinidade do solo. $\mathrm{O}$ algodoeiro (Gossypium hirsutum L.), classificado como tolerante à salinidade, tem uma SL de 7,7 $\mathrm{dS} \mathrm{m} \mathrm{m}^{-1}$ (AYERS; WESTCOT, 1999). Contudo, não é conhecida a tolerância desta espécie ao estresse salino durante a fase de crescimento inicial das plântulas.

O presente estudo teve como objetivo avaliar a tolerância à salinidade de diferentes cultivares de algodão (Gossypium hirsutum L.) durante a fase de emergência e estabelecimento inicial das plântulas.

\section{Material e Métodos}

O experimento foi realizado em casa-de-vegetação, na Universidade Estadual de Mato Grosso do Sul (UEMS), Unidade Universitária de Cassilândia-MS ( $51^{\circ} 48^{\prime}$ de longitude $\mathrm{W}, 19^{\circ} 05^{\prime}$ de latitude $\mathrm{S}$ e altitude média de $470 \mathrm{~m}$ ), no período de agosto a setembro de 2015. O clima da região, segundo classificação de Köppen, é do tipo tropical chuvoso (Aw), com verão chuvoso e inverno seco (precipitação no inverno menor que $60 \mathrm{~mm}$ ), precipitação e temperatura média anual de $1.520 \mathrm{~mm}$ e $24,1^{\circ} \mathrm{C}$, respectivamente. Por ser trabalho realizado em condições controladas estas informações são pouco relevantes

O delineamento experimental utilizado foi inteiramente casualizado disposto, em esquema fatorial 6 x 5, com quatro repetições. Os tratamentos consistiram em seis cultivares de algodoeiro (FM 910, FM 980 GLT, TMG 42 WS, TMG 82 WS, DP 1240 B2RR e DP 1228 B2R) e cinco níveis de salinidade da água de irrigação $\left(0,0 ; 2,5 ; 5,0,10,0\right.$ e $\left.20,0 \mathrm{dS} \mathrm{m}{ }^{-1}\right)$. Os diferentes níveis de salinidade foram obtidos pela dissolução de cloreto de sódio $(\mathrm{NaCl})$, em água destilada, ajustando-se com condutivímetro de bancada, com correção automática da temperatura.

Os testes foram realizados com uma amostra de 25 sementes por repetição, totalizando 100 sementes por tratamento. A qualidade fisiológica das sementes foi avaliada mediante as seguintes determinações:

Teste de emergência - a semeadura foi realizada em bandejas plásticas $(42 \times 28 \times 6 \mathrm{~cm})$, contendo como substrato a vermiculita de granulometria fina. A irrigação foi realizada diariamente conforme necessidade da cultura. Durante a fase de germinação das sementes, o número de plântulas emergidas foi avaliado diariamente até 14 dias após a semeadura; com 
os valores contabilizados, foram calculados a porcentagem de emergência (\%), índice de velocidade de emergência (IVE) e o tempo médio de emergência (TME) como apresentado a seguir:

Índice de velocidade de emergência - foram realizadas simultaneamente ao teste de emergência, tendo-se computado, diariamente e no mesmo horário, o número de plântulas que apresentavam dois cotilédones visíveis. O cálculo do índice foi realizado com fórmula proposta por Maguire (1962):

$$
\operatorname{IVE}=\left(\mathrm{E}_{1} / \mathrm{N}_{1}\right)+\left(\mathrm{E}_{2} / \mathrm{N}_{2}\right)+\left(\mathrm{E}_{3} / \mathrm{N}_{3}\right)+\ldots+\left(\mathrm{E}_{\mathrm{n}} / \mathrm{N}_{\mathrm{n}}\right)
$$

onde, IVE = índice de velocidade de emergência (plântulas $\operatorname{dia}^{-1}$ ); $E_{1}, E_{2}, E_{3}, \ldots, E n=$ número de plântulas emergidas computadas na primeira, segunda, terceira e última contagem; e, $\mathrm{N}_{1}, \mathrm{~N}_{2}, \mathrm{~N}_{3}, \ldots, \mathrm{N}_{\mathrm{n}}=$ número de dias da semeadura na primeira, segunda, terceira e última contagem (MAGUIRE, 1962).

Tempo médio de emergência - obtido por meio de contagens diárias das plântulas emergidas até a última contagem e calculado conforme Labouriau (1983):

$\mathrm{TME}=\Sigma\left(\mathrm{n}_{\mathrm{i}} \mathrm{t}_{\mathrm{i}}\right) / \Sigma \mathrm{n}_{\mathrm{i}}$

onde, TME = tempo médio de emergência (dias); $\mathrm{n}_{\mathrm{i}}$ = número de plântulas emergidas no intervalo entre cada contagem; $\mathrm{e}, \mathrm{t}_{\mathrm{i}}=$ tempo decorrido entre $\mathrm{o}$ início da emergência e a i-ésima contagem.

Após 14 dias de exposição aos diferentes níveis de salinidade, as plântulas foram retiradas das bandejas, e as raízes lavadas em água corrente para remoção do substrato. Posteriormente, determinou-se a altura, o comprimento da raiz principal, a matéria seca da parte aérea e das raízes, conforme descrito:

Altura e comprimento da raiz principal: ambas foram mensuradas em 15 plântulas tomadas aleatoriamente, com auxílio de régua graduada em milímetros. Os resultados expressos em centímetros.

Matéria seca da parte aérea e das raízes: A parte aérea e as raízes foram separadas, colocados em sacos de papel modelo 'Kraft' e levados para secar em estufa com circulação a $60{ }^{\circ} \mathrm{C}$, durante 72 horas. Após esse período, as amostras foram pesadas em balança analítica com precisão de $0,0001 \mathrm{~g}$, os resultados foram expressos em mg plântula ${ }^{-1}$ (NAKAGAWA, 1999).

Os dados obtidos foram submetidos à análise de variância, aplicando-se o teste $\mathrm{F}$ a $5 \%$ de probabilidade. As médias dos tratamentos foram comparadas pelo teste Tukey a $5 \%$ de probabilidade. Para as análises estatísticas, os dados expressos em porcentagem foram previamente transformados em $(x+0,5)^{0,5}$. As análises foram realizadas utilizando-se o software estatístico Sisvar versão 5.3 para Windows (FERREIRA, 2010).

\section{Resultados e Discussão}

Todos os parâmetros avaliados foram influenciados significativamente pela fonte de variação cultivar (Tabela 1). Tais resultados já são esperados, haja vista, que as cultivares tem características diferentes quanto ao background genético e outros atributos propiciando a existência de tais variações. Observou-se que apenas o índice de velocidade não foi influenciado pela fonte de variação nível de salinidade (Tabela 1). Para a interação cultivar versus salinidade verificou-se que não houve efeito significativo apenas para o índice de velocidade de emergência e a altura das plântulas. Assim, pode-se considerar que os cultivares de algodão possuem comportamento distinto em relação aos diferentes níveis de salinidade durante a fase de crescimento inicial das plântulas.

Independentemente do nível de salinidade, observou-se maiores valores médios de emergência e índice de velocidade de emergência em plântulas de algodão do cultivar DP 1228 B2RF; todavia, esta cultivar nos níveis de 10,0 e $20,0 \mathrm{dS} \mathrm{m}^{-1}$ não se diferenciou do cultivar DP 1240 B2RR (Tabela 2).

Em relação aos coeficientes de variação, constatouse que todas as variáveis mensuradas obtiveram baixa e média variação (Tabela 1). Para Pimentel Gomes (2000), os coeficientes de variação em torno de 0 a $10 \%$ e de 10 a $20 \%$ indicam a alta e média homogeneidade dos dados, respectivamente.

Tabela 1. Resultado da análise de variância para a emergência das plântulas (EME), índice de velocidade de emergência (IVE), tempo médio de emergência (TME), altura (ALT), comprimento da raiz principal (CR), matéria seca da parte aérea (MSPA) e matéria seca das raízes (MSR), obtidos no ensaio cultivares de algodão e níveis de salinidade da água de irrigação. Cassilândia-MS, 2015.

\begin{tabular}{lccccccc}
\hline Causas de variação & \multicolumn{9}{c}{ Probabilidade $>$ F } \\
\cline { 2 - 8 } & EME & IVE & TME & ALT & CR & MSPA & MSR \\
\hline Cultivar (C) & 0,013 & 0,003 & $<0,000$ & $<0,000$ & $<0,000$ & 0,010 & $<0,000$ \\
Salinidade (S) & $<0,000$ & 0,088 & $<0,000$ & $<0,000$ & $<0,000$ & $<0,000$ & $<0,000$ \\
C $\times$ S & $<0,000$ & 0,112 & $<0,000$ & 0,083 & 0,048 & 0,045 & $<0,000$ \\
\hline CV $(\%)$ & 5,35 & 6,72 & 7,86 & 6,85 & 11,81 & 7,34 & 10,32 \\
\hline
\end{tabular}

$\mathrm{CV}$ - Coeficiente de variação. 
Tabela 2. Valores médios para a emergência das plântulas, índice de velocidade de emergência e tempo médio de emergência das plântulas, obtidos no ensaio cultivares de algodão e níveis de salinidade da água de irrigação. Cassilândia-MS, 2015.

\begin{tabular}{|c|c|c|c|c|c|c|}
\hline \multirow{2}{*}{$\begin{array}{l}\text { Nível de salinidade } \\
\qquad\left(\mathrm{dS} \mathrm{m}^{-1}\right)\end{array}$} & \multicolumn{6}{|c|}{ Cultivar } \\
\hline & FM 910 & FM 980 GLT & TMG $42 \mathrm{WS}$ & TMG $82 \mathrm{WS}$ & DP 1240 B2RR & DP 1228 B2RF \\
\hline & \multicolumn{6}{|c|}{ Emergência (\%) } \\
\hline 0,0 & $13 \mathrm{bC}$ & $3 \mathrm{bD}$ & $18 \mathrm{bC}$ & $32 \mathrm{bB}$ & $14 \mathrm{cC}$ & $54 \mathrm{bA}$ \\
\hline 2,5 & $54 \mathrm{aB}$ & $37 \mathrm{aC}$ & $39 \mathrm{aC}$ & $33 \mathrm{bC}$ & $48 \mathrm{bB}$ & $74 \mathrm{aA}$ \\
\hline 5,0 & $21 \mathrm{bC}$ & $32 \mathrm{aC}$ & $46 \mathrm{aB}$ & $48 \mathrm{aB}$ & $64 \mathrm{aA}$ & $66 \mathrm{aA}$ \\
\hline 10,0 & $6 \mathrm{bC}$ & $0 \mathrm{bC}$ & $4 \mathrm{cC}$ & $25 \mathrm{bB}$ & $65 \mathrm{aA}$ & $78 \mathrm{aA}$ \\
\hline \multirow[t]{2}{*}{20,0} & $0 \mathrm{bA}$ & $0 \mathrm{bA}$ & $0 \mathrm{cA}$ & $0 \mathrm{cA}$ & $0 \mathrm{cA}$ & $0 \mathrm{cA}$ \\
\hline & \multicolumn{6}{|c|}{ Índice de velocidade de emergência (plântulas dia $^{-1}$ ) } \\
\hline 0,0 & $1,59 \mathrm{cC}$ & $0,43 \mathrm{bD}$ & $2,61 \mathrm{bC}$ & $4,92 \mathrm{bB}$ & $1,96 \mathrm{cC}$ & $7,38 \mathrm{cA}$ \\
\hline 2,5 & $8,83 \mathrm{aB}$ & $5,62 \mathrm{aC}$ & $5,87 \mathrm{aC}$ & $5,00 \mathrm{bC}$ & $7,35 \mathrm{bB}$ & $11,93 \mathrm{aA}$ \\
\hline 5,0 & $3,00 \mathrm{bC}$ & $4,64 \mathrm{aC}$ & $6,70 \mathrm{aB}$ & $6,75 \mathrm{aB}$ & $9,49 \mathrm{aA}$ & $9,56 \mathrm{bA}$ \\
\hline 10,0 & $0,75 \mathrm{cB}$ & $0,00 \mathrm{bB}$ & $0,40 \mathrm{cB}$ & $3,29 \mathrm{cB}$ & $8,92 \mathrm{aA}$ & $10,82 \mathrm{bA}$ \\
\hline \multirow[t]{2}{*}{20,0} & $0,00 \mathrm{dA}$ & $0,00 \mathrm{bA}$ & $0,00 \mathrm{cA}$ & $0,00 \mathrm{dA}$ & $0,00 \mathrm{dA}$ & $0,00 \mathrm{dA}$ \\
\hline & \multicolumn{6}{|c|}{ Tempo médio de emergência (dia) } \\
\hline 0,0 & $8,31 \mathrm{aA}$ & $7,00 \mathrm{aA}$ & $6,94 \mathrm{bA}$ & $6,59 \mathrm{aA}$ & $7,36 \mathrm{aA}$ & $7,37 \mathrm{aA}$ \\
\hline 2,5 & $6,31 \mathrm{aA}$ & $6,73 \mathrm{aA}$ & $6,74 \mathrm{bA}$ & $6,67 \mathrm{aA}$ & $6,60 \mathrm{aA}$ & $6,27 \mathrm{aA}$ \\
\hline 5,0 & $7,14 \mathrm{aA}$ & $7,03 \mathrm{aA}$ & $7,02 \mathrm{bA}$ & $7,25 \mathrm{aA}$ & $6,81 \mathrm{aA}$ & $6,95 \mathrm{aA}$ \\
\hline 10,0 & $8,00 \mathrm{aB}$ & $0,00 \mathrm{bC}$ & $10,00 \mathrm{aA}$ & 7,64 aB & $7,35 \mathrm{aB}$ & $7,27 \mathrm{aB}$ \\
\hline 20,0 & $0,00 \mathrm{bA}$ & $0,00 \mathrm{bA}$ & $0,00 \mathrm{cA}$ & $0,00 \mathrm{bA}$ & $0,00 \mathrm{bA}$ & $0,00 \mathrm{bA}$ \\
\hline
\end{tabular}

Médias seguidas da mesma letra, maiúscula na linha e minúscula na coluna, não diferem entre si pelo teste de Tukey a 5\%.

A diferença na emergência das plântulas entre os cultivares (Tabela 2), pode ser justificada, em parte, pelos diferentes níveis de vigor das sementes de algodão utilizadas. A emergência das plântulas de algodão foi afetada negativamente com o aumento dos níveis de salinidade da solução (Tabela 2). No tratamento submetido a $20,0 \mathrm{dS} \mathrm{m}^{-1}$ não houve emergência em nenhum dos cultivares de algodão assim também para o nível de 10,0 dS m${ }^{-1}$ do cultivar FM 980 GLT. Dessa forma, fica evidente que cada cultivar tem determinada tolerância aos níveis de salinidade. Segundo Furtado et al. (2007) as características fisiológicas e morfológicas de cada cultivar são determinadas pelo seu genótipo, sendo assim, há comportamentos divergentes em relação aos efeitos da salinidade. Os autores observaram diferenças na germinação entre os cultivares de algodoeiro submetidos à diferentes níveis de salinidade.

$\mathrm{O}$ algodoeiro é classificado como tolerante à salinidade até o nível de condutividade elétrica de 7,7 $\mathrm{dS} \mathrm{m}^{-1}$ (AYERS; WESTCOT, 1999). Entretanto, conforme já reportado essa tolerância depende da cultivar. Os cultivares DP 1240 B2RR e DP 1228 B2RF toleraram níveis de salinidade de até $10,0 \mathrm{dS} \mathrm{m}^{-1} \mathrm{e}$ mesmo nessas condições apresentaram emergência de 68 e $75 \%$, respectivamente.

O efeito da salinidade da água de irrigação na emergência das plântulas de algodoeiro pode estar relacionado às alterações do potencial hídrico do solo em função da presença dos sais. Com essas modificações, há redução do gradiente de potencial entre o solo e a superfície da semente e, consequentemente a absorção de água e o metabolismo germinativo das sementes são afetados (LOPES; MACEDO, 2008).

Os menores valores de emergência das plântulas foram obtidos no tratamento controle. Tais achados podem ser explicados devido ao excesso de retenção de água promovido pelo substrato utilizado (vermiculita), o que resultou em uma menor presença de oxigênio no meio e, consequente redução significativa na emergência das plântulas em alguns dos cultivares de algodão (Tabela 2).

Os diferentes níveis de salinidade resultaram em efeitos pouco expressivos no tempo médio de emergência das plântulas para a maioria dos cultivares de algodão (Tabela 2). O tempo médio de emergência equivale à média ponderada que expressa o espaço de tempo em dias nos quais ocorre a emergência de $50 \%$ das plântulas do tratamento (estande final). Com base nesta inferência, verifica-se que o tempo decorrido para ocorrer $50 \%$ da emergência das plântulas de algodão variou de 6,3 a 10,0 dias.

Seguindo a mesma tendência da porcentagem de emergência e do índice de velocidade de emergência (Tabela 2) os maiores valores médios da altura e comprimento radicular das plântulas de algodão foram obtidos para os cultivares DP 1228 B2RF e DP 1240 B2RR (Tabela 3). Entretanto, no tratamento controle 
houve diferença estatística apenas do cultivar FM 980 GLT; no nível de salinidade de $2,5 \mathrm{dS} \mathrm{m}^{-1}$ não diferiu do cultivar TMG 82 WS para ambos os parâmetros. Para altura de plântulas, no nível de $2,5 \mathrm{dS} \mathrm{m}^{-1}$ constatou-se que não houve diferença estatística entre os cultivares TMG 82 WS, 1228 B2RF e DP 1240 B2RR.

A altura e o comprimento radicular das plântulas de algodão foram afetadas negativamente pelos níveis de salinidade (Tabela 3). Observou-se os maiores valores destes parâmetros, nos tratamentos com a adição de 2,5 $\mathrm{dS} \mathrm{m}{ }^{-1}$ em todos cultivares e, 5,0 dS $\mathrm{m}^{-1}$ para os cultivares DP 1240 B2RR e FM 910. Nas concentrações

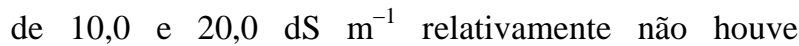
crescimento das plântulas de algodão (Tabela 3). Os menores valores médios da altura das plântulas e do comprimento radicular no tratamento controle devem-se ao excesso de água no substrato; com a respiração dos órgãos submersos da planta, o oxigênio $\left(\mathrm{O}_{2}\right)$ é esgotado tornando esse ambiente anóxico (FRIES et al., 2007). A hipoxia ou a anoxia sofrida pelo sistema radicular altera o metabolismo celular provocando queda imediata na respiração das raízes das plantas (LIAO; LIN, 2001). Quando o solo torna-se hipóxico, devido ao alagamento, as raízes são submetidas à uma condição de estresse e, deste modo, as plantas respondem com maior ou menor eficiência, permitindo a distinção de espécies e/ou cultivares tolerantes e intolerantes (BATISTA et al., 2008). Em plantas de soja, Amarante e Sodek (2006) constataram que a falta de $\mathrm{O}_{2}$ no sistema radicular pode inibir a fixação simbiótica e absorção de nitrogênio e outros minerais ocasionando pouco crescimento das raízes e nodulação, provavelmente, em virtude da exigência de oxigênio no processo de fixação.

Tabela 3. Valores médios para a altura, comprimento da raiz principal, produção de matéria seca da parte aérea e das raízes, obtidos no ensaio entre cultivares de algodão e níveis de salinidade da água de irrigação. Cassilândia-MS, 2015.

\begin{tabular}{|c|c|c|c|c|c|c|}
\hline \multirow{2}{*}{$\begin{array}{l}\text { Nível de salinidade } \\
\qquad\left(\mathrm{dS} \mathrm{m}^{-1}\right)\end{array}$} & \multicolumn{6}{|c|}{ Cultivar } \\
\hline & FM 910 & FM 980 GLT & TMG $42 \mathrm{WS}$ & TMG 82 WS & $\begin{array}{c}\text { DP } 1240 \\
\text { B2RR }\end{array}$ & $\begin{array}{c}\text { DP } 1228 \\
\text { B2RF }\end{array}$ \\
\hline & \multicolumn{6}{|c|}{ Altura $(\mathrm{cm})$} \\
\hline 0,0 & $2,64 \mathrm{bA}$ & $0,00 \mathrm{cB}$ & $3,51 \mathrm{bA}$ & $3,31 \mathrm{bA}$ & $2,67 \mathrm{bA}$ & $2,61 \mathrm{cA}$ \\
\hline 2,5 & 4,61 aB & $5,51 \mathrm{aB}$ & $4,95 \mathrm{aB}$ & $6,51 \mathrm{aA}$ & $6,73 \mathrm{aA}$ & $7,19 \mathrm{aA}$ \\
\hline 5,0 & $3,80 \mathrm{aB}$ & $3,59 \mathrm{bB}$ & $2,94 \mathrm{bC}$ & $2,44 \mathrm{bC}$ & $5,83 \mathrm{aA}$ & $4,72 \mathrm{bA}$ \\
\hline 10,0 & $0,00 \mathrm{cB}$ & $0,00 \mathrm{cB}$ & $0,00 \mathrm{cB}$ & $1,21 \mathrm{cA}$ & $2,24 \mathrm{bA}$ & $1,63 \mathrm{cA}$ \\
\hline \multirow[t]{2}{*}{20,0} & $0,00 \mathrm{cA}$ & $0,00 \mathrm{cA}$ & $0,00 \mathrm{cA}$ & $0,00 \mathrm{dA}$ & $0,00 \mathrm{cA}$ & $0,00 \mathrm{dA}$ \\
\hline & \multicolumn{6}{|c|}{ Comprimento da raiz principal $(\mathrm{cm})$} \\
\hline 0,0 & $4,90 \mathrm{bA}$ & $0,00 \mathrm{cB}$ & $6,50 \mathrm{bA}$ & $6,62 \mathrm{bA}$ & $5,32 \mathrm{bA}$ & $5,51 \mathrm{cA}$ \\
\hline 2,5 & $7,19 \mathrm{aC}$ & $9,05 \mathrm{aB}$ & $8,39 \mathrm{aB}$ & $10,85 \mathrm{aA}$ & $11,73 \mathrm{aA}$ & $12,51 \mathrm{aA}$ \\
\hline 5,0 & $6,02 \mathrm{aB}$ & $6,34 \mathrm{bB}$ & $6,23 \mathrm{bB}$ & $5,87 \mathrm{bB}$ & $10,55 \mathrm{aA}$ & $9,12 \mathrm{bA}$ \\
\hline 10,0 & $0,00 \mathrm{cC}$ & $0,00 \mathrm{cC}$ & $0,00 \mathrm{cC}$ & $3,61 \mathrm{cB}$ & $5,51 \mathrm{bA}$ & $4,27 \mathrm{cB}$ \\
\hline \multirow[t]{2}{*}{20,0} & $0,00 \mathrm{cA}$ & $0,00 \mathrm{cA}$ & $0,00 \mathrm{cA}$ & $0,00 \mathrm{dA}$ & $0,00 \mathrm{cA}$ & $0,00 \mathrm{dA}$ \\
\hline & \multicolumn{6}{|c|}{ Matéria seca da parte aérea $\left(\mathrm{mg} \mathrm{planta}^{-1}\right)$} \\
\hline 0,0 & $29,60 \mathrm{aC}$ & $0,00 \mathrm{bD}$ & $52,98 \mathrm{aB}$ & $64,49 \mathrm{aA}$ & $50,85 \mathrm{aB}$ & $43,97 \mathrm{aB}$ \\
\hline 2,5 & $31,85 \mathrm{aC}$ & $40,08 \mathrm{aC}$ & $51,90 \mathrm{aB}$ & $57,85 \mathrm{aB}$ & $69,47 \mathrm{aA}$ & $54,45 \mathrm{aB}$ \\
\hline 5,0 & $26,34 \mathrm{aC}$ & $39,47 \mathrm{aB}$ & $53,75 \mathrm{aA}$ & $44,70 \mathrm{bB}$ & $62,15 \mathrm{aA}$ & $44,50 \mathrm{aB}$ \\
\hline 10,0 & $0,00 \mathrm{bC}$ & $0,00 \mathrm{bC}$ & $0,00 \mathrm{bC}$ & $45,91 \mathrm{bB}$ & $57,01 \mathrm{aA}$ & $43,97 \mathrm{aB}$ \\
\hline \multirow[t]{2}{*}{20,0} & $0,00 \mathrm{bA}$ & $0,00 \mathrm{bA}$ & $0,00 \mathrm{bA}$ & $0,00 \mathrm{cA}$ & $0,00 \mathrm{bA}$ & $0,00 \mathrm{bA}$ \\
\hline & \multicolumn{6}{|c|}{ Matéria seca das raízes $\left(\mathrm{mg} \mathrm{planta}^{-1}\right)$} \\
\hline 0,0 & 7,40 aA & $0,00 \mathrm{cC}$ & $5,39 \mathrm{bA}$ & $5,39 \mathrm{bA}$ & $2,81 \mathrm{bB}$ & $3,25 \mathrm{cB}$ \\
\hline 2,5 & $5,55 \mathrm{bC}$ & $8,89 \mathrm{aB}$ & $8,71 \mathrm{aB}$ & $11,25 \mathrm{aA}$ & $13,23 \mathrm{aA}$ & $11,39 \mathrm{aA}$ \\
\hline 5,0 & $7,88 \mathrm{aB}$ & $4,21 \mathrm{bC}$ & $4,71 \mathrm{bC}$ & $3,37 \mathrm{bC}$ & $11,19 \mathrm{aA}$ & $7,69 \mathrm{bB}$ \\
\hline 10,0 & $0,00 \mathrm{cB}$ & $0,00 \mathrm{cB}$ & $0,00 \mathrm{cB}$ & $1,00 \mathrm{cB}$ & $3,51 \mathrm{bA}$ & $1,10 \mathrm{~dB}$ \\
\hline 20,0 & $0,00 \mathrm{cA}$ & $0,00 \mathrm{cA}$ & $0,00 \mathrm{cA}$ & $0,00 \mathrm{cA}$ & $0,00 \mathrm{cA}$ & $0,00 \mathrm{dA}$ \\
\hline
\end{tabular}

Médias seguidas da mesma letra, maiúscula na linha e minúscula na coluna, não diferem entre si pelo teste de Tukey a 5\%. 
De maneira geral, a produção de matéria seca aérea e radicular também foram afetadas negativamente pelos níveis de salinidade (Tabela 3). Cabe ressaltar que o sistema radicular foi mais afetado pelos níveis de salinidade do que a parte aérea. De acordo com Munns e Tester (2008) as altas concentrações de sais no solo, além de reduzir o potencial hídrico, podem provocar efeitos tóxicos nas plantas causando distúrbios funcionais e injúrias no metabolismo.

Em geral, os resultados obtidos confirmam os relatados por Daniel et al. (2011) ao avaliarem o crescimento inicial de plântulas de algodão em diferentes níveis de salinidade constataram que a altura das plântulas e da raiz principal foram negativamente afetadas em todas os cultivares estudados. Contudo, diferem dos resultados verificados por Oliveira et al. (2013) em que os parâmetros altura de planta, tamanho da raiz, diâmetro do caule e número de folhas de algodoeiro não diferiram estatisticamente quando submetidos aos diversos níveis de salinidade. Este fato está relacionado ao comportamento dos diferentes cultivares de algodão que foram utilizadas em cada ensaio.

O excesso de sais na solução do substrato altera a capacidade das plantas de absorver, transportar e utilizar os íons necessários para o seu crescimento e desenvolvimento (FEIJÃO et al., 2011). O desequilíbrio nutricional causado pela salinidade ocorre devido à competição na absorção e transporte dos nutrientes essenciais, às alterações estruturais na membrana e à inibição da atividade de várias enzimas-chave do metabolismo (ZHU, 2001; PARIDA; DAS, 2005; ARAGÃO et al., 2010).

A redução do crescimento inicial das plântulas de algodão pode estar relacionada à capacidade de absorção de água das plântulas em situação de altos níveis de salinidade. Para Dias e Blanco (2010) o aumento da pressão osmótica causado pelo excesso de sais solúveis na solução do solo poderá atingir um nível em que as plantas não terão força de sucção suficiente para superar o potencial osmótico e absorver água. A planta poderá também sofrer perda da água que se encontra no interior das raízes. Adicionalmente, há o custo metabólico de energia associado às adaptações ao estresse salino, incluindo a síntese de solutos orgânicos para proteção de macromoléculas e osmorregulação, a regulação do transporte e distribuição iônica em vários órgãos e dentro das células e a manutenção da integridade das membranas celulares (WILLADINO; CAMARA, 2004).

\section{Conclusões}

Os cultivares de algodão DP 1228 B2RF e DP 1240 B2RR apresentaram os melhores índices de emergência das plântulas até a condutividade elétrica da água de irrigação de 10,0 dS m$~^{-1}$, sugerindo que estes cultivares são moderadamente tolerantes ao estresse salino durante a fase de estabelecimento inicial das plantas. No entanto, o crescimento inicial desses cultivares são afetados negativamente a partir de 2,5 a $5,0 \mathrm{dS} \mathrm{m} \mathrm{m}^{-1}$, como reportado pelo decréscimo da altura, comprimento da raiz principal e matéria seca das raízes das plântulas.

Os cultivares de algodão FM 910, FM 980 GLT e TMG 42 WS são mais susceptíveis aos efeitos prejudiciais do estresse salino por apresentarem os menores índices de emergência e de crescimento inicial das plântulas.

A adição de altas concentrações de salinidade $(20,0$

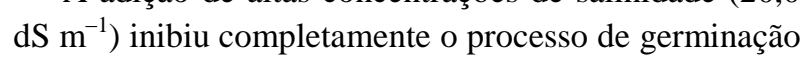
das sementes de todos os cultivares de algodão avaliados.

\section{Referências Bibliográficas}

AMARANTE, L.; SODEK, L. Waterlogging effect on xylem sap glutamine of nodulated soybean. Biologia Plantarum, Netherlands, v. 50, n. 3, p. 405-410, 2006.

ARAGAO, R. M.; SILVEIRA, J. A. G.; SILVA, E. N.; LOBO, A. K. M. L.; DUTRA, A. T. B. Absorção, fluxo no xilema e assimilação do nitrato em feijão-caupi submetido à salinidade. Revista Ciência Agronômica, Fortaleza-CE, v. 41, n. 01, p. 100-106, 2010.

AYERS, R. S.; WESTCOT, D. W. (trad.). A qualidade da água na agricultura. Campina Grande-PB: UFPB, 1999, 218 p.

BATISTA, C. U. N.; MEDRI, M. E.; BIANCHINI, E.; MEDRI, C.; PIMENTA, J. A. Tolerância à inundação de Cecropia pachystachya Trec. (Cecropiaceae): aspectos ecofisiológicos e morfoanatômicos. Acta Botânica Brasileira, Feira de Santana-BA, v. 22, n. 1, p. 91-98, 2008.

BRUNES, A. P.; FONSECA, D. A. R.; RUFINO, C. A.; TAVARES, L. C.; TUNES, L. M.; VILLELA, F. A. Crescimento de plântulas de aveia branca submetidas ao estresse salino. Semina: Ciências Agrárias, Londrina-PR, v. 34 , n. 6, p. 3455-3462, 2013

CRAMER, G. R.; ALBERICO, G. J.; SCHMIDT, C. Salt tolerance is not associated with the sodium accumulation of two maize hybrids. Australian Journal of Plant Physiology, Melbourne, v. 21, n. 5, p. 675-692, 1994.

DANIEL, V. C.; SEVILHA, R. R.; SILVA, F. F.; ZONETTI, P. C. Germinação e crescimento de plântulas de algodão colorido sob condições de estresse salino. Revista em Agronegócios e Meio Ambiente, Maringá-PR, v. 4, n. 2, p. 321-333, 2011.

DEBOUBA, M.; GOUIA, H.; VALADIER, M. H, GHORBEL, M. H.; SUZUKI, A. Salinity-induced tissuespecific diurnal changes in nitrogen assimilatory enzymes in tomato seedlings grown under high or low nitrate medium. Plant Physiology and Biochemistry, Maryland, v. 44, n. 5-6, p. 409-419, 2006. 
DIAS, N. S.; DUARTE, S. N.; YOSHINAGA, R. T.; TELES FILHO, J. F. Produção de alface sob diferentes níveis de salinidade do solo. Irriga, Botucatu-SP, v. 10, n. 1, p. 20-29, 2005.

DIAS, N. D.; BLANCO, F. F. Efeitos dos sais no solo e na planta. In: GHEYI, H. R.; DIAS, N. S.; LACERDA, C. F. Manejo da salinidade na agricultura: Estudos básicos e aplicados. Fortaleza-CE: Instituto Nacional de Ciência e Tecnologia em Salinidade, 2010. p. 129-140.

FEIJÃO, A. R.; SILVA, J. C. B.; MARQUES, E. C.; PRISCO, J. T.; GOMES-FILHO, E. Efeito da nutrição de nitrato na tolerância de plantas de sorgo sudão à salinidade. Revista Ciência Agronômica, Fortaleza-CE, v. 42, n. 3, p. 675-683, 2011.

FERREIRA, D. F. Sistema SISVAR para análises estatísticas. Lavras-MG: Universidade Federal de Lavras. 2010 .

FRIES, D. D.; ALVES, J. D.; DELÚ FILHO, N.; MAGALHÃES, P. C.; GOULART, P. F. P. Crescimento de plântulas do milho "saracura"e atividade de a-amilase e invertases associados ao aumento da tolerância ao alagamento exercido pelo cálcio exógeno. Bragantia, Campinas-SP, v. 66 , n. 1, p. 1-9, 2007.

FURTADO, R. F.; MANO, A. R. O.; ALVES, C. R.; FREITAS, S. M.; FILHO, S. M. Efeito da salinidade na germinação de sementes de algodão. Revista Ciência Agronômica, Fortaleza-CE, v. 38, n. 2, p. 224-227, 2007.

GUILHERME, L. R. G. G.; LIMA, J. M.; LOPES, A. S.; ALVAREZ V. V. H. (ed.). Tópicos em ciência do solo. v. 3. Viçosa-MG: Sociedade Brasileira de Ciência do Solo, 2003. p. 165-208.

LABOURIAU, L. G. A germinação das sementes. Washington: Secretaria Geral da Organização dos Estados Americanos, 1983. 174p.

LIAO, C. T.; LIN, C. H. Physiological adaptation of crop plants to flooding stress. Proceedings National Science Council, Taipei, v. 25, n. 3, p. 148-157, 2001.

LOPES, J. C.; MACEDO, C. M. P. Germinação de sementes de couve chinesa sob influência do teor de água, substrato e estresse salino. Revista Brasileira de Sementes, LondrinaPR, v. 30, n. 3, p. 079-085, 2008.

MAAS, E. V.; HOFFMAN, G. J. Crop salt tolerance - Current assessment. Jounal of Irrigation and Drainage Division, New York, v. 103, n. 2, p. 115-134, 1977.

MAGUIRE, J. D. Speed of germination aid in selection and evaluation for seedling emergence and vigor. Crop Science, Madison, v. 2, n. 1, p. 176-177, 1962.
MEDEIROS, P. R. F.; DUARTE, S. N.; DIAS, C. T. S. Tolerância da cultura do pepino a salinidade em ambiente protegido. Revista Brasileira de Engenharia Agrícola e Ambiental, Campina Grande-PB, v. 13, n. 4, p. 406-410, 2009.

MUNNS, R. Comparative physiology of salt and water stress. Plant, Cell and Environment, Oxford, v. 25, n. 2, p. 239250, 2002.

MUNNS, R.; TESTER, M. Mechanisms of salinity tolerance. Annual Review of Plant Biology, Oxford, v. 59, n. 1, p. 651681,2008

NAKAGAWA, J. Testes de vigor baseados no desempenho das plântulas. In: KRZYZANOWSKI, F. C.; VIEIRA, R. D.; FRANÇA-NETO, J. B. Vigor de sementes: conceitos e testes. Londrina-PR: ABRATES, 1999. cap. 2, p. 9-13.

OLIVEIRA, L. L. P.; DIAS, N. S.; FARIAS, W. C.; MEDEIROS, L. C.; FERREIRA, L. L. Tolerância de cultivares de algodão (Gossypium hirsutum) à salinidade da água de irrigação. Revista Verde, Mossoró-RN, v. 8, n. 4, p. 232-237, 2013.

PARIDA, A. K.; DAS, A. B. Effects of $\mathrm{NaCl}$ stress on nitrogen and phosphorous metabolism in a true mangrove Bruguiera parviflora grown under hydroponic culture. Journal of Plant Physiology, Irvine, v. 161, n. 8, p. 921-928, 2004.

PARIDA, A. K.; DAS, A. B. Salt tolerance and salinity effects on plants: a review. Ecotoxicology and Environment Safety, New York, v. 60, p. 324-349, 2005.

PIMENTEL-GOMES, F. Curso de Estatística Experimental. 14 ${ }^{\mathrm{a}}$ ed. Piracicaba-SP: Degaspari, 2000. 477 p.

RIBEIRO, M. R.; FREIRE, F. J.; MONTENEGRO, A. A. A. 2003. Solos halomórficos no Brasil: Ocorrência, gênese, classificação, uso e manejo sustentável. In: CURI, N.; MARQUES, J. J.; GUILHERME, L. R. G.; LIMA, J. M.; LOPES, A. S; ALVAREZ, V. H. (eds.). Tópicos em Ciência do Solo. Viçosa: Sociedade Brasileira de Ciência do Solo, v.3, p.165-208.

SILVA, E. F. F.; CAMPECHE, L. F. S. M.; DUARTE, S. N.; FOLEGATTI, M. V. Evapotranspiração, coeficiente de cultivo e de salinidade para o pimentão cultivado em estufa. Magistra, Cruz das Almas-BA, v. 17, n. 2, p. 58-69, 2005.

WILLADINO, L.; CAMARA, T. R. Origen y naturaleza de los ambientes salinos. In: REIGOSA, M. J.; PEDROL, N.; SÁNCHEZ, A. (ed.). La ecofisiología vegetal - Uma ciencia de síntesis. Madrid: Thompson, 2004. p.303-330.

ZHU, J. K. Plant salt tolerance. Trends Plant Science, Oxford, v. 6, n. 02, p. 66-71, 2001. 